\title{
A delicious fly in the soup. The relationship between disgust, obesity, and restraint
}

Citation for published version (APA):

Houben, K., \& Havermans, R. C. (2012). A delicious fly in the soup. The relationship between disgust, obesity, and restraint. Appetite, 58(3), 827-830. https://doi.org/10.1016/j.appet.2012.01.018

Document status and date:

Published: 01/06/2012

DOI:

10.1016/j.appet.2012.01.018

Document Version:

Publisher's PDF, also known as Version of record

Document license:

Taverne

Please check the document version of this publication:

- A submitted manuscript is the version of the article upon submission and before peer-review. There can be important differences between the submitted version and the official published version of record.

People interested in the research are advised to contact the author for the final version of the publication, or visit the DOI to the publisher's website.

- The final author version and the galley proof are versions of the publication after peer review.

- The final published version features the final layout of the paper including the volume, issue and page numbers.

Link to publication

\footnotetext{
General rights rights.

- You may freely distribute the URL identifying the publication in the public portal. please follow below link for the End User Agreement:

www.umlib.nl/taverne-license

Take down policy

If you believe that this document breaches copyright please contact us at:

repository@maastrichtuniversity.nl

providing details and we will investigate your claim.
}

Copyright and moral rights for the publications made accessible in the public portal are retained by the authors and/or other copyright owners and it is a condition of accessing publications that users recognise and abide by the legal requirements associated with these

- Users may download and print one copy of any publication from the public portal for the purpose of private study or research.

- You may not further distribute the material or use it for any profit-making activity or commercial gain

If the publication is distributed under the terms of Article $25 \mathrm{fa}$ of the Dutch Copyright Act, indicated by the "Taverne" license above, 
Short communication

\title{
A delicious fly in the soup. The relationship between disgust, obesity, and restraint
}

\author{
Katrijn Houben*, Remco C. Havermans \\ Clinical Psychological Science, Maastricht University, P.O. Box 616, 6200 MD Maastricht, The Netherlands
}

\section{A R T I C L E I N F O}

\section{Article history:}

Received 16 November 2011

Received in revised form 16 January 2012

Accepted 18 January 2012

Available online 25 January 2012

\section{Keywords:}

Obesity

Dietary restraint

Disgust

Food

\begin{abstract}
A B S T R A C T
Disgust is a core emotion that serves to protect one from engaging in activities that promote contamination and contracting disease. Since disgust is intimately connected to ingesting food, disgust sensitivity is probably also associated with dietary habits. The aim of the present study was to examine the relationship between obesity and disgust and between restraint and disgust. Participants $(n=135$, all female) were recruited and tested via the Internet. They indicated their desire to eat high-calorie foods and filled out several questionnaires assessing restrained eating and disgust sensitivity. We hypothesized that more restrained eaters would show increased disgust and that women with a higher BMI would show decreased disgust, which is what we found; that is, more restrained eaters showed increased core disgust and contamination disgust, whereas women with a higher BMI showed decreased core disgust and contamination disgust. Hence, feeling disgusted by food may be a strategy to uphold restraint, whereas relatively decreased disgust could encourage overeating.
\end{abstract}

(c) 2012 Elsevier Ltd. All rights reserved.

\section{Introduction}

Disgust has long been considered a powerful way of protecting us from things that could harm us or make us sick. For instance, we find rotting fruits, or meat crawling with maggots disgusting, triggering avoidance of such food products. Disgust, thus, is a basic emotion that works as a powerful inhibitor to prevent contamination and disease (Olatunji \& Sawchuk, 2005; Rozin, Haidt, \& McCauley, 1998). Disgust is typically conceived as a food rejection response, intended to avoid the ingestion of harmful, toxic items (Haidt, McCauley, \& Rozin, 1994; Rozin \& Fallon, 1987). As a guardian of the mouth, disgust seems intimately connected to eating behavior, and may even be involved in the development and maintenance of eating disorders.

In the domain of eating disorders, avoiding high calorie food is often considered to be of paramount importance since (over) consumption of such food products may cause undesirable weight gain and overweight. Importantly, one way of facilitating the avoidance of food may be to infuse it with disgusting properties (e.g., Griffiths \& Troop, 2006; Harvey, Troop, Treasure, \& Murphy, 2002). Indeed, women with eating disorders, including anorexia nervosa, bulimia nervosa, and eating disorders not otherwise specified, display increased disgust specifically toward food and the human body compared to healthy controls (Davey, Buckland, Tantow, \& Dallos, 1998; Harvey et al., 2002; Troop, Treasure, \& Serpell, 2002). Hence, eating disorders seem to be characterized by increased disgust in domains that are related to eating and weight,

\footnotetext{
* Corresponding author.

E-mail address: K.Houben@maastrichtuniversity.nl (K. Houben).
}

suggesting that disgust-related emotional responses may be a defensive mechanism to support the avoidance of high calorie foods.

In a similar vein, one could also expect elevated levels of disgust in people who are high in dietary restraint. Restrained eaters chronically attempt to restrict their food intake to avoid becoming overweight, but are generally unsuccessful and characterized by frequent lapses of restraint (e.g., Fedoroff, Polivy, \& Herman, 1997; Herman \& polivy, 1980; Jansen \& van den Hout, 1991). Possibly, restrained eaters also transform food into forbidden substances via disgust, in which case they should show enhanced food-related disgust (e.g., Griffiths \& Troop, 2006). Findings in this area, however, are mixed: While Muris et al. (2000) found no relationship between dietary restraint and food-related disgust, Griffiths and Troop (2006) found a positive relationship between food-related disgust and restrained eating. In contrast to what was expected, however, increased food-related disgust did not coincide with greater avoidance of high calorie food (Griffiths \& Troop, 2006).

Importantly, previous research focused primarily on disgust in both clinical and non-clinical samples with an intense fear of becoming overweight. Obesity, on the other hand, is characterized by excess body weight and a strong desire to consume palatable, high calorie food. Consequently, disgust might be reduced in obese patients, which could at least partly explain their increased appetite. In contrast to this hypothesis, Griffiths and Troop (2006) found no relationship between disgust and weight. However, it should be noted that in this study, disgust was measured directly with respect to food products rather than using a validated measure of disgust sensitivity. 
Therefore, the aim of the present study was to further examine the relationship between obesity and disgust as well as the relationship between restraint and disgust using the revised disgust scale, which assesses disgust sensitivity in three separate domains: (1) core disgust, which refers to a sense of offensiveness and the threat of disease, including disgust towards rotting foods, and the willingness to try unusual food products; (2) contamination-based disgust, which reflects the perceived threat of contagion, including contamination of food products by bad hygiene or disease; and (3) animal-reminder disgust, which reflects the aversion of reminders of our own mortality and our animal origin (Olatunji et al., 2007). In line with previous findings, it was expected that dietary restraint would be associated with increased disgust sensitivity, particularly on the core disgust and contamination-based disgust subscales that are related to food products. Further, it was expected that overweight and obesity would be related to reduced disgust sensitivity on the same food-related subscales. Finally, we also examined the relationship between disgust sensitivity and the desire to eat high calorie food. It was hypothesized that increased disgust would be related to a decreased appetite for high calorie food.

\section{Method}

\section{Participants}

Participants were 135 females (age: $M=27.36, S D=11.33$ ) who completed this study in return for a gift certificate. All participants were recruited via advertisements for volunteers to participate in research on eating habits on Internet websites and forums.

\section{Materials and measures}

Body mass index

Participants reported their weight and height to calculate their Body Mass Index (BMI), which is the ratio of weight to squared height $\left(\mathrm{kg} / \mathrm{m}^{2}\right)$.

\section{Restraint scale}

Dietary restraint was measured using the Restraint Scale (RS; Herman \& Polivy, 1980). The RS is a self-report questionnaire consisting of 10 items assessing concern for dieting and weight fluctuations. The maximum score on this scale is 35 , while the minimum score is 0 . Higher scores indicate an increased intention to restrict food intake.

\section{Disgust scale-revised}

Disgust was measured with the 25-item Disgust Scale-Revised (DS-R; Haidt et al., 1994; Olatunji et al., 2007). The DS-R consists of three subscales: A 12-item core disgust scale, an 8-item animalreminder scale, and a 5 -item contamination disgust scale (Olatunji et al., 2007). The DS-R includes 13 items for which participants indicated on a 5-point scale whether they agreed or disagreed with a given statement ( $0=$ completely disagree; $4=$ completely agree $)$ and 12 items for which participants rated the extent to which they would find a given experience disgusting on a 5-point scale ( 0 = not disgusting; 4 = extremely disgusting). The DS-R further included two catch items, which were left out in the analyses.

\section{Desire to eat}

Participants were shown six pictures of high caloric food (i.e., chips, nuts, chocolate, French fries, pizza, and fried appetizers) in successive order. For each food item, participants rated on a 7point scale how much they would like to eat the food product ( 1 = strongly dislike; 7 = strongly like).

\section{Procedure}

All participants were recruited and tested via the Internet. Advertisements invited people to our website, where they received further information and a consent form. After giving consent, participants were presented the pictures of high calorie food and evaluated their desire to eat these products. Next, participants filled out the RS as well as their weight and height to calculate BMI. Finally, participants filled out the DS-R.

\section{Results}

Participants had a mean score of 13.51 on the RS ( $S D=6.48$; range $1-30)$ and a mean $\mathrm{BMI}$ of $23.76(S D=5.03$, range 13.86 39.86). BMI and RS scores were significantly correlated, $r=.45$, $p<.001$. However, neither BMI nor RS scores correlated significantly with the desire to eat high calorie food, $r=.02$, ns., and $r=.01, n s$., respectively. The three subscales of the DS-R were significantly correlated: Core disgust was correlated with both animal-reminder disgust, $r=.58, \quad p<.001$, and contamination disgust, $r=.46, p<.001$, while animal-reminder disgust was also correlated with contamination disgust, $r=.37, p<.001$. Further, core disgust and contamination disgust were significantly correlated with the desire to eat high calorie food, $r=-.22, p=.01$ and $r=-.17, p=.05$, respectively, so that lower disgust scores were associated with an increased desire to eat high calorie food. Animal-reminder disgust, in contrast was not significantly correlated with the desire to eat, $r=-.12, n s$.

The effects of dietary restraint and BMI on disgust were examined, separately for the three subscales of the DS-R, using Univariate Analyses of Covariance (ANCOVA) with dietary restraint scores and BMI as (standardised) continuous covariates (van Breukelen \& van Dijk, 2007). Means for high versus low dietary restraint and high versus low BMI are estimated at respectively 1 $S D$ above and below the mean. With respect to core disgust, results showed a significant effect of both restraint, $F(1,131)=5.89$, $p=.02$, and BMI, $F(1,131)=4.30, p=.04$. The interaction between restraint and BMI was not significant $(F<1)$. As shown in Fig. 1, core disgust was elevated in high-restrained eaters compared to low-restrained eaters. Participants with a higher BMI, in contrast, showed reduced core disgust compared to participants with a lower BMI (see Fig. 2). Similarly, there was also a significant effect of restraint status, $F(1,131)=6.05, p=.02$, and BMI, $F(1,131)=4.17$, $p=.04$, on contamination disgust, while the interaction term was not significant $(F<1)$. While restrained eaters showed stronger contamination disgust than unrestrained eaters (see Fig. 1), participants with a higher BMI showed less contamination disgust compared to participants with a lower BMI (see Fig. 2). On the animalreminder subscale, neither the main effects of restraint and BMI, nor their interaction reached significance (all $F \leqslant 1.52$ ).

\section{Discussion}

The aim of the present study was twofold: First, it was examined whether obesity is associated with reduced disgust, reflecting the increased appetite displayed by overweight people. Second, in replication of previous findings by Griffiths and Troop (2006), it was examined whether dietary restraint is related to increased disgust, reflecting the predisposition of restrained eaters to try to avoid eating high calorie food. In line with these predictions, people with overweight (i.e., a higher BMI) showed elevated levels of 


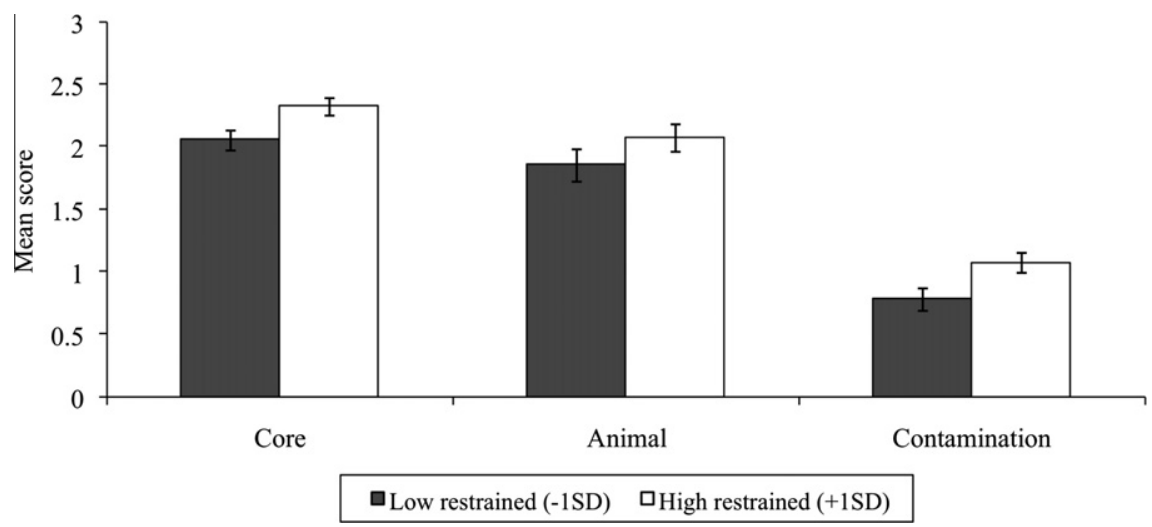

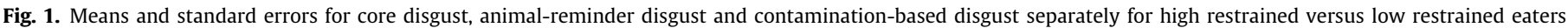
(respectively $1 S D$ above or below the mean restraint score).

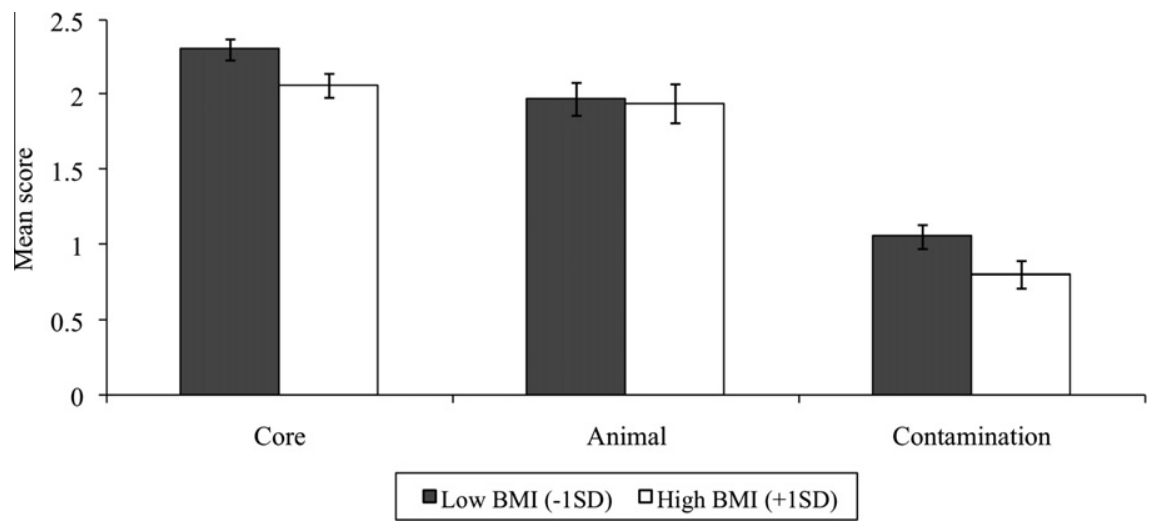

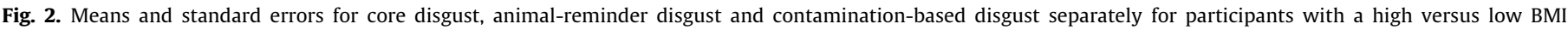
(respectively $1 S D$ above or below the mean BMI).

core disgust and contamination-based disgust compared to people without overweight (i.e., a lower BMI). However, overweight was not related to differences on the animal-reminder disgust subscale. Similarly, core disgust and contamination-based disgust also differentiated between people high versus low in dietary restraint in such a way that increased dietary restraint was associated with increased disgust on these subscales. The animal-reminder subscale again did not differentiate between high and low restraint status. Finally, levels of core disgust and contamination disgust were related to the desire to eat high calorie food.

As explained in the introduction, core disgust sensitivity reflects disgust based on the perceived threat of oral ingestion and the threat of disease (Olatunji and Sawchuk, 2005; Olatunji et al., 2007). As such, core disgust reflects people's disposition to evaluate disease-carrying characteristics of substances, including food products (Olatunji and Sawchuk, 2005). For instance, spoiled milk, soup stirred with a (thoroughly washed) flyswatter, and unusual food products such as monkey meat may be perceived as threatening and repugnant and therefore trigger avoidance. The present findings show that such sensitivity to core disgust elicitors discriminates between people high versus low in dietary restraint as well as between people with high versus low BMI. Moreover, increased core disgust sensitivity was associated with a reduced desire to eat palatable, high calorie food. Together these findings suggest that restrained eaters' may imbue palatable food products with disgusting properties in an attempt to facilitate avoidance of these products. Thus, increased core disgust sensitivity might serve as a strategy to restrict food intake. Overweight people, in contrast, appear to have a higher threshold for rejecting food products, which may explain their predisposition to overeat.

Contamination-based disgust also differed between high versus low restrained eaters and between people with high versus low BMI. In addition, increased contamination disgust was also associated with a decreased desire to eat high calorie food. Contamination-based disgust refers to disgust reactions based on perceived threat of contagion (Olatunji and Sawchuk, 2005; Olatunji et al., 2007), for instance by a cook with the common cold, or another person sipping from one's drink. Importantly, as was the case with core disgust, contamination-based disgust was decreased in people with overweight and increased in restrained eaters. Again, these differences in disgust sensitivity may reflect the tendency to overeat in people who are overweight and who are not as easily repulsed by contamination of food products. In restrained eaters, in contrast, higher contamination-based disgust may again act as a protection mechanism against overeating.

Finally, animal-reminder disgust sensitivity refers to the aversion of stimuli that remind us of our mortality and our animal origin (Olatunji and Sawchuk, 2005; Olatunji et al., 2007). Thus, animal-reminder disgust sensitivity is not as strongly related to eating and aversion by food products as core disgust and contamination-based disgust. Unsurprisingly then, animal-reminder disgust sensitivity did not correlate with the desire to eat and was also unrelated to dietary restraint and BMI.

Thus, the current findings indicate that dietary restraint is related to elevated levels of food-related disgust, while overweight is associated with lower food-related disgust. While Griffiths and Troop (2006) also showed increased levels of disgust toward food 
in restrained eaters compared to unrestrained eaters, they did not find a relationship between disgust and BMI. This discrepancy could be due to the use of different disgust measures in these two studies: Whereas Griffiths and Troop (2006) used a state-related measure of disgust specifically for high and low calorie food products, we used a more general, trait-related measure of disgust sensitivity. Importantly, the food-specific disgust measure did not correlate with eating behavior in the study by Griffiths and Troop (2006), while food-related trait disgust sensitivity was related to the desire to eat high calorie food in the present study. Hence, these findings suggest that these two measures may tap different constructs with the latter playing a more important role in eating behavior. It should be noted that Griffiths and Troop (2006) also used a trait-related measure of disgust in addition to their state disgust measures. However, the subscales of this trait disgust measure were never correlated with dietary restraint, BMI or eating behavior as in the present study so that the two studies cannot be compared in this respect.

Finally, there are two limitations with respect to the current study that need to be addressed. First, we did not include hunger ratings in this study. Importantly, individual differences in hunger may have influenced the relationship between disgust and desire to eat so that especially hungry participants show reduced levels of disgust sensitivity and also more desire to eat. This possibility that the association between desire to eat and disgust may have been influenced or caused by hunger needs to be further examined in future research. Second, we did not measure actual food consumption but instead relied on self-reported desire to consume high calorie food, which may be sensitive to pressure to give socially desirable answers. This could in part explain why we did not find a relationship between BMI or restraint and the desire to eat high calorie food. Therefore, it would be interesting to examine in future research whether actual food consumption correlates with food-related disgust sensitivity, and whether disgust mediates the relationship of BMI and restraint status with consumption behavior.

In conclusion, people with overweight appear less easily offended and repulsed by properties that may signal disease or contagion, and as a result are less often disgusted by food products, which may explain their increased appetite. In contrast, restrained eaters, who chronically attempt to restrict their food intake show enhanced sensitivity to disgusting properties of food products, which may reflect a defensive mechanism designed to facilitate avoidance of food. Whether disgust is indeed causally related to dietary restraint and overweight needs to be further examined in future research. Nevertheless, this study adds to the growing body of evidence that disgust, and in particular food-related disgust, is related to abnormal eating patterns and eating disorders.

\section{References}

Davey, G. C. L., Buckland, G., Tantow, B., \& Dallos, R. (1998). Disgust and eating disorders. European Eating Disorders Review, 6, 201-211.

Fedoroff, I. C., Polivy, J., \& Herman, C. P. (1997). The effect of pre-exposure to food cues on the eating behaviour of restrained and unrestrained eaters. Appetite, 28, 33-47.

Griffiths, J., \& Troop, N. A. (2006). Disgust and fear ratings of eating disorderrelevant stimuli. Associations with dieting concerns and fat intake. Anxiety, Stress, and Coping, 19, 421-433.

Haidt, J., McCauley, C., \& Rozin, P. (1994). Individual differences in sensitivity to disgust. A scale sampling seven domains of disgust elicitors. Personality and Individual Differences, 16, 701-713.

Harvey, T., Troop, N. A., Treasure, J. L., \& Murphy, T. (2002). Fear, disgust, and abnormal eating attitudes. A preliminary study. International Journal of Eating Disorders, 32, 213-218.

Herman, C. P., \& Polivy, J. P. (1980). Restrained eating. In A. J. Stunkard (Ed.), Obesity (pp. 208-225). Philadelphia: Saunders.

Jansen, A., \& Van den Hout, M. (1991). On being led into temptation. 'Counterregulation' of dieters after smelling a 'preload'. Addictive Behaviors, 5, 247-253.

Muris, P., Merckelbach, H., Nederkoorn, S., Rassin, E., Candel, I., \& Horselenberg, R. (2000). Disgust and psychopathological symptoms in a nonclinical sample. Personality and Individual Differences, 29, 1163-1167.

Olatunji, B. O., \& Sawchuk, C. N. (2005). Disgust. Characteristic features, social manifestations, and clinical implications. Journal of Social and Clinical Psychology, 24, 932-962.

Olatunji, B. O., Williams, N. L., Tolin, D. F., Abramowitz, J. S., Sawchuk, C. N., Lohr, J. M., et al. (2007). The disgust scale. Item analysis, factor structure, and suggestions for refinement. Psychological Assessment, 19, 281-297.

Rozin, P., \& Fallon, A. (1987). A perspective on disgust. Psychological Review, 94, 23-41.

Rozin, P., Haidt, J., \& McCauley, C. (1998). Disgust. The body and soul emotion. In T. Dalgleish \& M. Power (Eds.), Handbook of Cognition and Emotion (pp. 429-445). Chichester, Sussex: Wiley.

Troop, N. A., Treasure, J. L., \& Serpell, L. (2002). A further exploration of disgust in eating disorders. European Eating Disorders Review, 10, 218-226.

van Breukelen, G. J. P., \& van Dijk, K. R. A. (2007). Use of covariates in randomized controlled trials. Journal of International Neuropsychological Society, 13, 903-904. 